\title{
REPRESENTAÇÕES DO APRENDER LÍNGUAS EM NARRATIVAS VISUAIS: O QUE MOSTRAM AS IMAGENS DE SITES DE ESCOLAS DE INGLÊS
}

\author{
Renato Caixeta da Silva ${ }^{{ }^{*}}$ \\ ${ }^{1}$ Centro Federal de Educação Tecnológica de Minas Gerais, Belo Horizonte, MG, Brasil
}

\begin{abstract}
Resumo
Este artigo trata do discurso sobre aprender línguas construído e veiculado por imagens em sites de escolas particulares especializadas em ensino de idiomas estrangeiros, evidenciando as representações construídas por esses estabelecimentos para a sociedade em geral. Argumenta-se a favor da consideração de imagens nos estudos da linguagem, e são adotadas, como referencial teórico, a visão sociossemiótica de linguagem, a Gramática do Design Visual e as ideias de representação social. A análise do corpus evidencia a representação de uma aprendizagem em condições ideais de conforto, homogeneidade, com recursos diversos, o aluno agente de processos relacionados à recepção linguística. Conclui-se que as narrativas visuais referendam a ideia comumente veiculada na sociedade de que o ensino de idiomas ideal acontece nos cursos de línguas e não na escola regular, reservado a poucas pessoas.

Palavras-chave: Semiótica Social; Gramática do Design Visual; Narrativas Visuais; Aprendizagem de Línguas Estrangeiras.
\end{abstract}

\section{REPRESENTATIONS OF LEARNING LANGUAGES IN VISUAL NARRATIVES: WHAT THE IMAGES OF ENGLISH SCHOOL SITES SHOW}

\begin{abstract}
This article is about the discourse on learning languages construed and transmitted by images in websites of private schools specialized in foreign languages teaching, evidencing the representations construed by these establishments to society. The argument favors the consideration of images in language studies, and the theoretical basis adopted includes the socio-semiotic approach to language, the Grammar of Visual Design, and the concept of social representation. The corpus analysis evidences the representation of the learning in optimal conditions of comfort,
\end{abstract}

\footnotetext{
${ }^{*}$ Professor titular do Centro Federal de Educação Tecnológica de Minas Gerais (CEFET-MG), onde atua desde 1997. É professor de inglês, docente permanente do Programa de Pós-Graduação em Estudos de Linguagens do CEFET-MG e do Curso de Letras - Bacharelado em Tecnologias da Edição, no qual leciona Leitura de Imagens. Coordena o Grupo de Pesquisa em Materiais e Recursos Didáticos (CNPq), e tem como temas de pesquisa principais as questões relativas a materiais didáticos e discursos sobre o ensinar e o aprender, usando como referencial teórico principal a visão de linguagem como semiótica social. E-mail: rencaixe@yahoo.com. br. ORCID: https://orcid.org/0000-0003-3274-3071.
} 
homogeneity, with the presence of resources and diverse instruments, in which the student is an agent of processes related to linguistic reception. It is concluded that these visual narratives contribute to the idea widely spread in society that the ideal language learning happens in private specialized schools and is reserved for few people.

Keywords: Social Semiotics; Grammar of Visual Design; Visual Narratives; Language Learning 


\section{Introdução}

Diz o ditado popular que "uma imagem vale mais que mil palavras". Entretanto, em estudos acadêmicos, muitas vezes, os modos semióticos (imagens e código verbal, por exemplo) têm sido considerados como independentes, isto é, um não depende do outro para existir para que significados sejam produzidos. Essa tem sido a perspectiva da Semiótica Social, teoria de linguagem adotada neste artigo e na pesquisa apresentada. Nessa visão de linguagem, pode-se dizer que uma imagem vale tanto quanto uma palavra, mas são modos diferentes e independentes de se criar e comunicar significados. Esse é um dos pressupostos da Gramática do Design Visual (KRESS, VAN LEEUWEN, 2006), e de toda a perspectiva de estudos sobre multimodalidade nessa linha teórica (por exemplo, KRESS, 2010; PIMENTA et alli, 2009; VAN LEEUWEN, 2004; 2005).

Vivemos num mundo saturado por imagens (HEMAIS, 2009), em que somos rodeados e bombardeados por vários tipos delas: estáticas ou em movimento, desenhos, fotografias, gráficos e infográficos, vídeos analógicos ou digitais. As imagens estão presentes nas mais diversas áreas de atuação humana, como nas artes, na religião, na educação, na medicina, nas ciências da natureza, nas engenharias, na comunicação em geral, como no jornalismo e na publicidade; via diferentes mídias, como jornais e revistas, televisão, Internet, aplicativos e dispositivos móveis (JOLY, 2007). Estudá-las, e assim investigar os vários significados construídos por e com elas na sociedade, é, portanto, uma necessidade, e envolve diversas áreas do conhecimento, dependendo do meio em que as imagens estão imersas e da área em que o estudo acontece.

Em se tratando de representações envolvendo agentes dos contextos escolares, trabalhos acadêmicos na área de estudos da linguagem têm focado o discurso verbal, utilizando-se de referenciais da análise do discurso para entender o que dizem professores e alunos. Exemplo disso pode ser comprovado pela publicação de Silva, Abud e Castro (2010), a tese de Silva (2012), a dissertação de Oliveira (2015), a tese de Repolês (2019), para mencionar apenas alguns estudos. Esses trabalhos aqui mencionados procuram analisar os dizeres de discentes e docentes sobre diferentes aspectos do ensino ou da aprendizagem: o livro didático, o ensino de gramática, a avaliação, a prática docente, a formação, a motivação, dentre outros. Pouco, entretanto, tem-se pesquisado acerca das representações construídas sobre o ensinar e o aprender em discursos engendrados pelas instituições de ensino, os discursos institucionais, na publicidade, e especificamente veiculados pelo uso de imagens. Ressalta-se, no entanto, o trabalho de Coracini (2003) que, em outra perspectiva teórica de discurso, analisa material de divulgação impresso de escolas de idiomas retratando a construção dos sentidos engendrados no texto verbal desse material, mostrando também a construção de promessas relativas ao ensino de idiomas.

O trabalho de Coracini (2003), especificamente, analisa os dizeres contidos nos panfletos disponibilizados em balcões de atendimento de escolas de línguas, e se aproxima da pesquisa aqui apresentada em termos de objeto de análise e 
alguns resultados encontrados. A autora, entretanto, adota outra perspectiva de análise discursiva, embasando sua investigação nos estudos foucaultianos e lacanianos, e procura mostrar como o discurso da mídia é "parte da constituição da identidade de professores e alunos" (CORACINI, 2003, p. 53).

Nos trabalhos mencionados nos dois últimos parágrafos, excetuando Silva (2012), o discurso estudado é somente aquele veiculado por meio do código verbal.

Por outro lado, nas Ciências Sociais, a partir da década de 1980, o uso de imagens em pesquisas começa a ser enfatizado e aceito numa busca por novas metodologias e técnicas de pesquisa (RIOS, COSTA, MENDES, 2016). Assim, o uso de imagens em pesquisas na área social implica considerar não apenas o grau de objetividade aparentemente revelado sobre um fato, mas o caráter interpretativista da pesquisa.

Essa importância atribuída a "ler", produzir e interpretar criticamente a linguagem visual permitiu transformar a perspectiva imagética em mais do que simples "realidade objetiva", porém instrumento do cientista social para entender os significados engendrados pelas imagens, suas formas de produção e mediação de sentido. (RIOS, COSTA, MENDES, 2016, p. 103).

Nesse sentido, pode-se dizer que uma pesquisa interpretativista e crítica de cunho discursivo, como a apresentada neste artigo, envolve:

a. Levar a imagem a sério, especialmente pela sua historicidade, contextualização e, ao mesmo tempo, autonomia de efeitos em relação ao objeto-referente;

b. Pensar sobre as condições sociais e efeitos dos objetos visuais;

c. Considerar a forma pela qual o pesquisador está analisando a imagem, compreendendo que nenhum olhar sobre a fotografia é inocente. Dessa forma, é necessário refletir sobre o viés crítico do próprio pesquisador (RIOS, COSTA, MENDES, 2016, p. 108).

Embora os autores enfatizem a fotografia no item c, consideram-se, neste artigo, os mais diversos tipos de imagem (fotografia, desenho, infográfico, colagem), e entende-se que a afirmativa acima pode se estender a esses tipos.

Nos anos 1990, a partir dos estudos da Linguística Sistêmico-Funcional e da Gramática Sistêmico-Funcional da Língua Inglesa (HALLIDAY, 1994; HALLIDAY e MATHIESSEN, 2004), Kress e van Leeuwen desenvolveram a Gramática do Design Visual (KRESS e VAN LEEUWEN, 2006), que descreve o uso das imagens na cultura ocidental. Nesta obra, entende-se que a linguagem (e a comunicação visual é um tipo de linguagem) é usada para representar as experiências e a percepção de mundo que temos (metafunção ideacional), estabelecer relações entre as pessoas (metafunção interpessoal) e para criar e organizar as mensagens (metafunção textual). Pode-se dizer que os estudos nessa perspectiva teórica têm caminhado a partir do estudo da língua como um modo semiótico em direção à 
consideração dos outros modos semióticos na comunicação humana, aplicandose ao estudo da linguagem como um todo. É, também, a consideração da multimodalidade, um fenômeno que existe desde que o ser humano começou a se comunicar, que pode ser definida como a junção de vários modos semióticos num evento comunicacional para a construção de significados, estado normal da condição humana de comunicação (KRESS, 2010, p. 1-5).

Na perspectiva do que foi mencionado até então, o presente artigo tem como objetivo apresentar uma análise do discurso sobre aprender línguas presente em sites de escolas de idiomas, construído por meio de imagens, de modo a evidenciar as representações visuais desse processo construídas e veiculadas por esses estabelecimentos para a comunidade em geral. Entende-se por representações os conhecimentos práticos construídos na sociedade via discursos sobre as mais diversas ações, pessoas, objetos, eventos, a partir de uma dada realidade sociocultural (MOSCOVICI, 2003), conhecimentos esses orientados para os processos de comunicação e de compreensão do meio social em que se encontra o ser humano (JODELET, 1995). E essa construção se dá no cotidiano, no senso comum, muitas vezes via os meios de comunicação que, com isso, acabam controlando forma e conteúdo do que se diz e como se age.

Considera-se o site um gênero discursivo em que há uma coleção de arquivos na web sobre um assunto (COSTA, 2008) - no caso, sobre a escola de línguas e seus cursos. Um site pode ter várias páginas; pode ser de caráter institucional, como os que são fonte das imagens analisadas na pesquisa. Essas escolas de línguas são instituições privadas que ofertam serviços educacionais voltadas para a aprendizagem de línguas, portanto o que se veicula nos sites é um discurso institucional, e assim o que se mostra e se representa como aprender línguas é o que a instituição escolar entende ser tal ação.

Nesse sentido, depreender as representações veiculadas sobre o aprender idiomas, sobretudo inglês, em sites de escolas de línguas se justifica pela necessidade de se entender o que é veiculado sobre tal processo na sociedade atual por essas instituições. Elas são procuradas por boa parte da população para aprender determinado idioma, o qual muitas vezes não é ensinado no sistema de ensino regular, ou é ensinado de modo que não satisfaz as necessidades e os desejos dos aprendizes com relação à língua estrangeira, como mostrado por Barcelos (2006).

De forma semelhante, Dutra (2016) também expõe que mesmo em face à importância enfatizada nos documentos oficiais sobre o ensino de línguas estrangeiras nos últimos anos no Brasil, os alunos universitários (portanto aqueles que já terminaram a educação básica) não demonstram proficiência nem sensação de ter aprendido uma língua estrangeira ao longo da Educação Básica.

Mais ainda, sendo o ser humano ideologicamente posicionado, este estudo pode revelar as construções ideológicas sobre a ação "aprender" materializadas nas imagens que compõem sites das instituições particulares e especializadas em ensino de línguas, e que constroem discursos uma vez que a imagem é um modo semiótico. Assim, as imagens acabam tendo uma chancela social para disseminação deste discurso e das representações. 
Se o objeto de estudo são representações do aprender línguas, e aprender é um processo, uma ação, são as representações visuais narrativas (KRESS, VAN LEEUWEN, 2006) o foco da análise empreendida. Mais adiante, o conceito de representações visuais narrativas adotado é desenvolvido.

Este artigo, então, está organizado da seguinte maneira. Após essa introdução, amplia-se a justificativa do trabalho sobre o estudo de imagens nos estudos de linguagens e apresenta-se a ideia de linguagem como semiótica social, incluindo os pressupostos da Linguística Sistêmico-Funcional e as noções básicas da Gramática do Design Visual para se entender as representações de narrativas visuais. Em seguida, é apresentada a metodologia de trabalho; nela mostra-se a constituição do corpus e procedimentos de análise deste. A análise e interpretação são expostas de modo a se propor uma compreensão sobre como o aprender línguas tem sido mostrado à sociedade por meio da veiculação das imagens nos sites em questão. Todos os procedimentos descritos servem de apoio para as considerações feitas ao final do artigo.

\section{As imagens nos estudos de linguagem}

Joly (2007) destaca o uso das imagens em várias áreas do conhecimento e da atuação humana. Ainda assim, segundo a autora, é difícil definir o termo, visto que há vários usos da palavra na sociedade: expressões como "imagem no espelho" (reflexo), "imagem da empresa" (imagem mental, ideia a respeito, ethos), "usar imagem na fala e na escrita" (metáforas e metonímias), "imagem fotográfica" (fotografia), "exame de imagem" (ultrassom, raio X), "imagem via satélite” (transmitida instantaneamente). Joly, então, propõe que se pense a imagem considerando que sua produção está ligada ao ser humano de alguma maneira, e argumenta:

O mais notável é que, apesar da diversidade dos significados desta palavra, compreendemo-la. Compreendemos que ela designa algo que, embora não remetendo sempre para o visível, toma de empréstimo alguns traços ao visual e, em todo o caso, depende da produção de um sujeito: imaginária ou concreta, a imagem passa por alguém, que a produz ou a reconhece. (JOLY, 2007, p.13)

Assumindo também que a imagem passa por alguém que a produz e a reconhece, entende-se que há aí um processo comunicacional, e que nesse processo acontece a construção e veiculação de significados. Consequentemente, há disseminação de representações sociais por meio de textos imagéticos, as quais são resultado das ações e convenções socioculturais. A apropriação desses significados construídos na linguagem em geral origina saberes construídos nos vários meios de atuação do homem, principalmente no cotidiano, e esses saberes de certa forma controlam as atividades humanas. São as representações sociais (MOSCOVICI, 2003). Quando se entende as representações de um grupo específico, compreende-se os conhecimentos construídos em torno de determinada coisa 
- no caso, o aprender línguas - no universo cotidiano (SÁ, 1998), influenciando a formação de condutas, modificando e reinventando os contextos.

$\mathrm{Na}$ área de estudos da linguagem, van Leeuwen (2004) argumenta que os linguistas devem dar atenção à comunicação visual. Segundo o autor, na contemporaneidade os denominados atos de fala poderiam e deveriam ser considerados atos comunicacionais, pois comumente mais de um modo semiótico está envolvido numa combinação de vários signos para alguém agir de acordo com uma intenção. Ainda segundo o mesmo autor, os gêneros do discurso (orais e escritos) combinam sempre diferentes modos (língua escrita, imagem, cores, tipografia, fala, gestos, olhar, posicionamento espacial) e, em determinados momentos de realização dos gêneros, nem sempre o elemento verbal está presente ou é o mais importante. Muitas vezes, um elemento visual é importante para a ligação entre partes de um texto exemplar de um gênero, como o negrito ou outra fonte (para se considerar a tipografia como um modo semiótico) que marcam subtítulos e separações em textos acadêmicos. É comum, argumenta van Leeuwen (2004), que elementos visuais e linguísticos possam estar intrinsecamente ligados num mesmo enunciado, como por exemplo, em propagandas e logomarcas. O autor acrescenta (também KRESS e VAN LEEUWEN, 2006; KRESS, 2010) que muitos dos conceitos desenvolvidos no estudo da gramática e do texto verbal servem também a outros modos semióticos. No caso da pesquisa apresentada neste artigo, as imagens são parte dos sites que se compõem também de textos escritos, e ajudam a veicular os significados construídos e expressos nestes textos bem como os significados não expressos na escrita.

Ao defender o que foi exposto no parágrafo anterior, van Leeuwen (2004) assume que todo texto é multimodal (assim como KRESS e VAN LEEUWEN, 2001; KRESS, 2010), e argumenta que os atos comunicativos têm natureza multimodal; isto é, neles há sempre a combinação de vários recursos semióticos (recursos de significação) que são usados dependendo da intenção do usuário do código no momento da comunicação. Argumenta ainda que na sociedade contemporânea a língua escrita, as imagens e os recursos gráficos, juntos, embora independentes, contribuem para a construção de significados. Por serem independentes, imagem e elemento verbal podem, inclusive, realizar significados contrastantes se observados em separado, mas ambos contribuem para a construção de algo que somente poderia ser pensado se considerados em conjunto.

Assumindo isso, este trabalho encontra respaldo também em Kress e van Leeuwen (2006, p.18), que tomam o componente visual de um texto como "uma mensagem organizada e estruturada de maneira independente". Ainda, nem tudo que é comunicado por meio do código verbal é possível de ser comunicado por meio do código visual, e vice-versa.

Essa visão de independência, então, guia a pesquisa apresentada neste artigo. São consideradas as imagens dos sites de cursos de línguas, apenas, independentes do texto escrito que acompanham. Muitas vezes, percebe-se, nos sites, que a imagem não está totalmente ligada ao texto escrito, e que uma imagem pode ser usada mais de uma vez, posta junto ou próxima a diferentes mensagens escritas 
em diferentes seções dos sites. Assim, elas são usadas enquanto código semiótico para engendrarem um discurso independente do que se veicula pelo código verbal escrito.

Neste artigo, assume-se também que os estudos do discurso e a Linguística Aplicada devem considerar as imagens e seus usos. Nos estudos de Linguística Aplicada (incluindo aqueles ligados ao ensino e à aprendizagem de línguas), as imagens podem ser vistas como forma de produzir e comunicar significados, portanto, uso real da linguagem na sociedade - o que se aproxima do objeto da Linguística Aplicada descrito por Almeida Filho (2011, p. 23): "o problema ou a questão real de uso de linguagem colocados na prática social dentro ou fora do contexto escolar".

As imagens, como modo de significação, participam muitas vezes da construção de discursos, derivam de e revelam modos de ações do ser humano na sociedade. Dessa forma, este artigo ajuda a entender como, na sociedade, mais especificamente por meio dos discursos das escolas especializadas de línguas estrangeiras, a aprendizagem de inglês e outros idiomas vem sendo representada. Em outras palavras, a pergunta que se quer responder é: que visão e imaginário de aprender se passam à sociedade nestes sites via imagens pelas escolas especializadas?

Por fim, tem-se o argumento de Moita Lopes (2006) em prol de uma Linguística Aplicada mais in(ter)disciplinar: os estudiosos da área devem também navegar por outros campos do saber - psicologia, sociologia, filosofia, antropologia -, e acrescento aqui o design visual.

Este trabalho investigativo alinha-se, então, à teoria sociossemiótica de linguagem, teoria mostrada a seguir. A visão de língua e linguagem como semiótica social iniciada por Michael Halliday como teoria de estudo da língua (código verbal) não desconsidera outros tipos de linguagem (outros códigos semióticos), e os pressupostos da Linguística Sistêmico-Funcional desenvolvidos por este autor têm guiado estudos relativos a imagens e outros códigos semióticos (cor, música, organização espacial, tipografia).

\section{A Linguística Sistêmico-Funcional e a Gramática do Design Visual}

A visão de linguagem como semiótica social conforme defendido por Halliday (1979) e seus seguidores, preocupa-se com o processo de significação. Este é visto como uma construção social, portanto realizada pelas pessoas usuárias de um código semiótico, as quais escolhem, nos sistemas presentes nesse código semiótico, os elementos necessários e desejados para a construção de significados. Essas escolhas são guiadas pelos interesses dos usuários e pelo contexto social em que eles se inserem. A ênfase está no processo de produção do signo (semiose), que envolve a produção, reprodução, circulação de significados de diferentes modos semióticos. Em outras palavras, o foco é como as pessoas usam artefatos comunicativos e eventos para interpretá-los em situações sociais e práticas específicas, daí a produção de signo ser uma ação social (NATIVIDADE; PIMENTA, 2009). 
Orientam os estudos nessa perspectiva, então, os princípios da Linguística Sistêmico-Funcional, conforme explicam Natividade e Pimenta (2009), Kress (2010), Halliday e Mathiessen (2004). Um desses princípios é a noção de escolha, já mencionada. Outro princípio é a noção de contexto - contexto de situação e contexto de cultura - que guia as escolhas semióticas. Por fim, a noção de funções da linguagem, também denominadas metafunções (ideacional, interpessoal, textual), as quais são, nesta vertente teórica, sinônimo de uso da linguagem.

Kress \& van Leeuwen (2006) apresentam a Gramática do Design Visual, considerando que a linguagem visual, assim como as várias modalidades semióticas (verbal, gestual, música, por exemplo), possui suas potencialidades e limitações próprias, e significados construídos por meio de imagens são diferentes daqueles construídos através de outros códigos. A noção de texto, então, é ampliada ao se considerar que todo texto é multimodal (KRESS, 2000); isto é, nele existem diferentes modalidades de construção e comunicação de significados, embora uma possa ter predominância sobre outras. Portanto, as linguagens, como a verbal e a visual, por exemplo, possuem maneiras distintas e formas específicas de realizar sistemas de significação próprios de determinadas culturas.

Assim, os autores argumentam que imagens são interpretadas no interior de uma dada cultura, e devem ser entendidas com base nas formas e modos de expressão disponíveis naquele contexto específico de comunicação, considerando-se os seus diferentes usos e valores. A Gramática do Design Visual (KRESS; VAN LEEUWEN, 2006), então, apresenta os elementos e as regras da cultura ocidental, a qual, na contemporaneidade, é a cultura dominante em termos de comunicação visual, cultural e tecnologicamente controlada pelas mídias de massa.

Pode-se dizer que nesta cultura ocidental está a cultura brasileira, mais especificamente a atividade educacional no Brasil. Dentro desse contexto, está o ensino de idiomas, altamente influenciado pelas escolas especializadas, que dominam as mídias de comunicação, promovem e produzem materiais didáticos para si e para outros estabelecimentos, colocam-se na sociedade como opção para uma aprendizagem de línguas estrangeiras bem sucedida (CORACINI, 2003).

A Gramática do Design Visual é, então, baseada na Gramática SistêmicoFuncional de Michael Halliday, construída com base nas ideias já mencionadas. Kress e van Leeuwen, entretanto, renomeiam as metafunções: a metafunção ideacional como representacional, a metafunção interpessoal como interacional, e a metafunção textual como composicional. Embora essas metafunções tenham sido brevemente explicadas na Introdução desse artigo, aqui são explicadas com mais detalhes no que se refere ao uso de imagens.

Em termos ideacionais, ou representacionais, as imagens podem representar narrativas ou conceitos. Narrativas, foco do presente trabalho, envolvem um processo, ao qual está ligado um ou mais participantes. A visão do processo pode ser evidenciada pelo traçado de um vetor, como exposto no exemplo na figura 1 abaixo, retirado do corpus. O processo e os participantes acontecem e ou aparecem em determinadas circunstâncias que podem ou não ser visíveis (cenários, instrumentos, ou companhias). Os processos podem ser de ação ou reação de 
agentes, direcionadas a uma meta - participante ao qual a ação é direcionada que pode ser visível na imagem (ação ou reação transacional), ou não (ação ou reação não transacional). Também há representação de ações mentais e verbais com recursos de balões (o que será também questionado na análise de dados), a representação de eventos cíclicos (em que um participante meta vira agente de outro processo), e ou simbólicos representados geometricamente.

Os participantes podem ser pessoas, animais, coisas, partes do corpo, seres animados ou inanimados representados nas imagens, ou podem ser representados de maneira simbólica. As circunstâncias podem ser o local detalhado ou não onde a cena acontece (cenário), podem ser também instrumentos utilizados pelos participantes na execução dos eventos, e as companhias que aparecem na imagem e não necessariamente tomam parte no evento focalizado na narrativa. Veremos, ao longo da análise, que essas categorias podem ser ampliadas e repensadas com o corpus pesquisado. A figura 1 exemplifica o que foi apresentado nos últimos parágrafos.

Figura 1: Exemplificação de representação narrativa

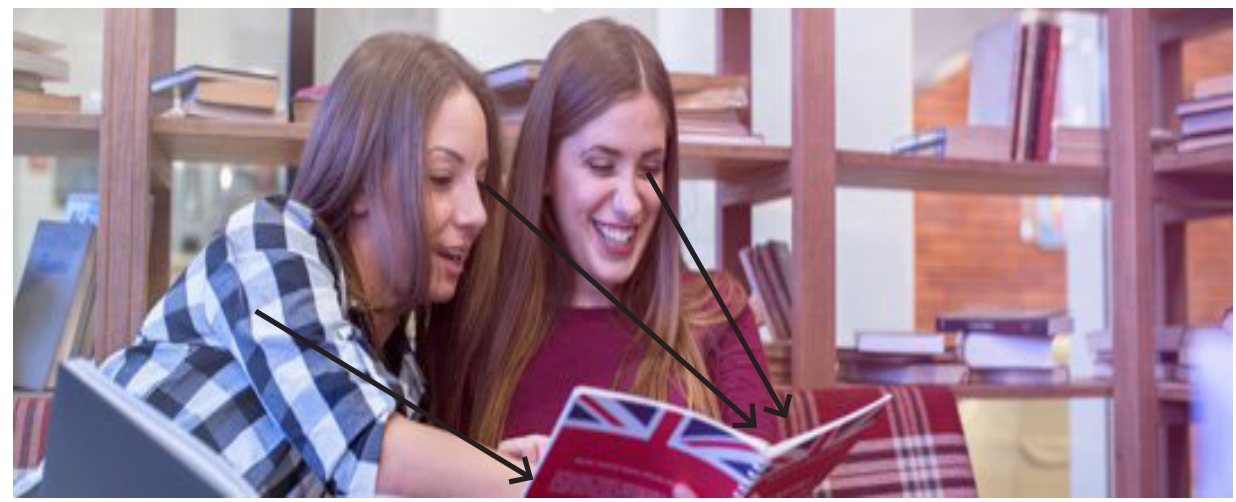

Fonte: Dados da pesquisa - escola 1 imagem 13.

Nesta imagem, há duas participantes femininas adultas, que leem e ou veem algo num livro - ações transacionais - e reagem sorrindo ao que veem e leem reação transacional. Os vetores (setas em preto) mostram a direção dos olhares das participantes e do braço de uma delas tendo como meta o que está no livro. A cena acontece num cômodo destinado à guarda de livros, uma espécie de biblioteca ou sala de estudos, mas não muito claramente evidenciado.

Já as representações de conceitos podem ser de três naturezas: processos classificatórios, quando a ênfase recai na categorização por determinadas características específicas; processos analíticos, quando se pretende mostrar ou realçar as partes constituintes de um todo; e processo simbólico, quando o que se mostra é importante por ser o que ou quem é, tendo uma simbologia no contexto de uso da imagem. Imagens de conceitos não foram consideradas na pesquisa, tendo em vista que o foco seria na representação do ato de aprender, portanto narrativa.

Quanto aos aspectos interacionias, são três os sistemas de elementos que contribuem para a construção de uma interação entre o que é representado e o 
observador. Primeiramente, se há ou não um olhar direcionado ao observador, e caso haja, diz-se que há uma demanda; isto é, o observador é convidado a interagir diretamente com o participante representado. Ao contrário, quando não há este direcionamento ao observador por meio de um olhar, tem-se uma situação de oferta, pois o que se representa é mostrado para contemplação do observador (o que acontece, por exemplo, na imagem da Figura 1). Em segundo lugar, há uma distância social criada entre participante representado e observador por meio de planos curtos, médios ou longos, os quais, respectivamente, podem resultar em mais proximidade e identificação (no caso da Figura 1 novamente), uma posição de respeito e credibilidade, e um distanciamento com ênfase na ação ou na situação como um todo. Por fim, o uso de perspectiva ou não contribui para a construção da interação entre observador e participante representado. A presença de perspectiva, como na figura apresentada no exemplo, revela uma atitude de subjetividade, pois o que é visto é mostrado de um ângulo específico, enquanto a ausência indica mais objetividade na medida em que revela "tudo" que há para ser visto.

Com relação à composição, a Gramática do Design Visual considera três sistemas de elementos que concorrem para a construção de significados dessa natureza: valor da informação, saliência e molduras. $O$ valor da informação refere-se ao posicionamento das informações na página (centralizado, polarizado horizontal ou verticalmente), sendo que cada posição revela a importância de um elemento na mensagem - informação já conhecida versus informação nova (Dado-Novo, polarização horizontal), situação idealizada e elemento concreto e real (Ideal-Real, polarização vertical), informação enfatizada e importante em contraposição à informação complementar e periférica (Centro-Margem). Já com relação à saliência, vários recursos podem ser usados para evidenciar elementos da composição imagética: cores, tamanho, plano, tipografia, foco, dentre outros. As molduras, visíveis por meio da linha, caixas coloridas, ou construídas com espaços brancos são usadas para separar informações, destacando-as, ao passo que a ausência de molduras pode indicar mais entrosamento entre as informações constantes na composição visual.

No caso da pesquisa em tela, nas imagens consideradas, foram observados aspectos de cunho representacional, interacional bem como aspectos composicionais. Toma-se por base que as três metafunções contribuem conjuntamente para a construção de representações, e não apenas a metafunção ideacional (SILVA, 2012).

Tendo já apresentado o objeto de pesquisa, os argumentos que justificam esta pesquisa e a teoria que a sustenta, passa-se à metodologia adotada.

\section{Metodologia: constituição de corpus, registro de informações e procedimentos de análise}

A pesquisa ora apresentada é qualitativa, descritiva e interpretativista. Foram coletadas imagens de sites de escolas de línguas estrangeiras de modo a se ter um corpus que permitisse investigar e interpretar os usos das imagens que mostram narrativas relativas ao aprender línguas. 
Foram selecionadas apenas imagens que são representações narrativas do ato de aprender e foram analisadas apenas uma vez, embora apareçam em diferentes seções dos sites, em que descrevem aspectos do curso e ou vantagens das escolas. Isso, porque o foco deste trabalho recai nas imagens apenas, no discurso engendrado e veiculado por meio delas, não na parte verbal do site. Às vezes, a parte verbal foi considerada apenas por se entender que ali se mostra as seções em que as imagens estão alocadas, mas não se pretendeu analisar o que é dito entendendo que isso está além do objetivo da pesquisa ora apresentada.

O corpus analisado para este trabalho é composto de 43 imagens de sites de quatro escolas de idiomas, todos visitados entre julho e agosto de 2018. As escolas fazem parte de redes nacionais com unidades em várias localidades brasileiras, incluindo a cidade em que atua o pesquisador. Três dessas escolas são redes de franquias e uma delas é um centro binacional como outros trinta e cinco semelhantes ligados à embaixada de um país em que o inglês é língua oficial e primeira. A consulta aos sites revelou que as imagens não eram diferentes nos sites referentes a escolas de diferentes localidades, pois há uma padronização de cursos, método, materiais didáticos, informações, imagens. Com isso, pode-se dizer que o corpus evidencia representações imagéticas que circulam pelo Brasil via sites dessas escolas de línguas.

A constituição do corpus levou em conta a saturação do mesmo, isto é, a percepção pelo pesquisador de que os recursos de significação e os significados veiculados nas imagens se repetiam. Isso indica que o pesquisador pode interromper a coleta quando percebe que não há novidades nos dados coletados. Conforme Gaskell (2008, p. 71),

... temas comuns começam a aparecer, e progressivamente sente-se uma confiança crescente na compreensão emergente do fenômeno. A certa altura, o pesquisador se dá conta de que não aparecerão novas surpresas ou percepções. Neste ponto de saturação do sentido, (...) se a avaliação do fenômeno é corroborada, é um sinal de que é tempo de parar.

No caso desta pesquisa, percebeu-se que os recursos de significação se repetiam em imagens no mesmo site, em sites diferentes e em outros que não entraram na constituição do corpus embora tenham sido consultados. Isso quer dizer que, embora as imagens sejam diferentes, os temas e recursos de significação são muito semelhantes, fazendo com que as imagens mostrem narrativas semelhantes.

Para uniformizar a coleta e guiar melhor a análise, a partir do referencial da Gramática do Design Visual foi elaborada uma ficha de coleta de informações. Esta ficha possui espaços para registro do nome da escola, número da imagem (dado pelo pesquisador), seção (ou seções) do site em que a imagem aparece, tipo de imagem (desenho, fotografia, gráfico, infográfico), e espaço para cópia da imagem. Além disso, com base na Gramática do Design Visual, foram constituídas seções em que se pudessem registrar, de maneira rápida e eficaz, as categorias observadas. Há também espaço para um registro verbal descritivo da imagem feito pelo pesquisador. A figura 2 mostra este instrumento elaborado para a pesquisa. 
Figura 2: Ficha de coleta de informações para análise de imagens

\section{IDENTIFICAÇÃO DE IMAGENS EM SITES DE ESCOLAS DE LÍNGUAS NARRATIVAS VISUAIS DE APRENDIZAGEM}

Site / escola:

Tipo de imagem: foto ( ) desenho ( ) gráfico ( ) tabela ( ) infográfico ( ) emoticons

( ) outros ( )

A imagem: (espaço para cópia da imagem)

Seção do site em que a imagem aparece:

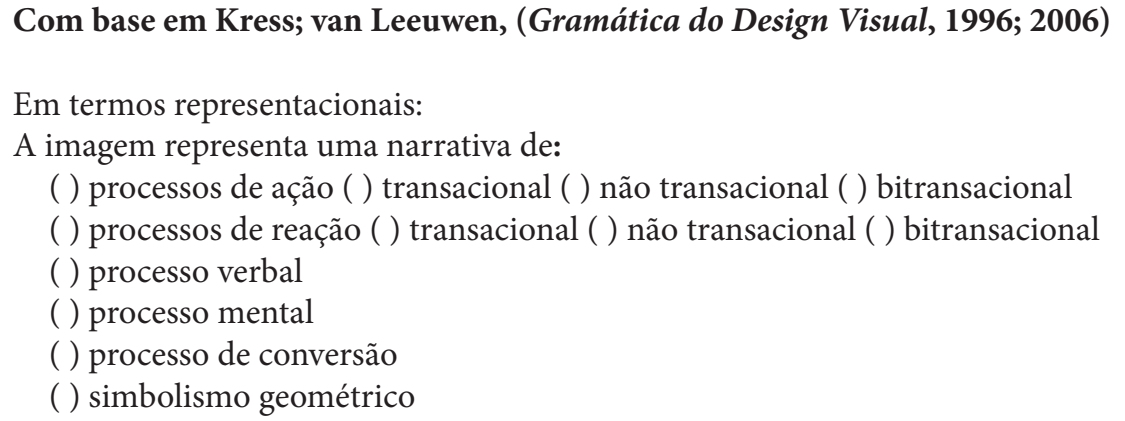

Circunstância: Cenário: Instrumentos: Acompanhamento:

Análise descritiva:

Em termos interacionais

Na imagem, percebe-se: ( ) demanda OU ( ) oferta / ( ) tomada curta OU ( ) tomada média OU ( ) tomada longa / ( ) perspectiva OU ( ) ângulo reto

Observação:

Em termos composicionais:

Valor da informação: Centralização:

Saliência: ( ) cor , ( ) tamanho Polarização: ( ) primeiro plano , ( )outro

Moldura: ( ) presença: __ linha contínua, linha tracejada, caixa colorida, ( ) ausência de molduras

Fonte: Elaborada pelo pesquisador

Para cada imagem encontrada e analisada foi preenchida uma ficha de registro. As imagens foram codificadas da seguinte maneira: "escola $\mathrm{n}^{\circ}$ imagem $\mathrm{n}^{0}$ ". Assim, por exemplo, "escola 1 imagem 3" refere-se à terceira imagem captada do primeiro site pesquisado. Todas as 43 fichas foram salvas em formato .docx e consultadas para a análise. Após arquivamento, foi feita uma tabulação das categorias previstas no instrumento. Todas as fichas foram revistas e fez-se uma segunda tabulação de modo a se obter números que mostrassem a recorrência de padrões discursivos construídos pelo uso das imagens.

A análise levou em conta a recursividade das categorias previstas, as observações recorrentes registradas pelo pesquisador na análise descritiva, sempre com a 
tentativa de se estabelecer padrões discursivos e interpretar as representações construídas no e pelo discurso imagético. Com isso, entende-se ser possível apresentar como a aprendizagem de línguas estrangeiras é representada discursivamente por meio das imagens nos sites de instituições que se propõem a promover essa aprendizagem. A partir desses procedimentos, então, apresenta-se a análise a seguir.

\section{Análise}

Inicia-se a análise pela própria constituição do corpus. Das 43 imagens coletadas em que há representações narrativas do aprender, 41 são fotografias e duas são infográficos. Esses infográficos representam e explicam o processo de aprender realizado em dois dos quatro estabelecimentos. Este uso de fotografias remete ao papel desse tipo de imagem na sociedade contemporânea. A fotografia traz credibilidade e fidedignidade aos fatos (KAWAKAMI, VEIGA, 2012), seriam tomadas como registros de algo que "realmente acontece" em determinado momento no tempo. Portanto, o que se mostra sobre aprender línguas nas escolas é feito de modo a ser acreditado pelo visitante do site, o qual pode ser um possível aluno ou pessoa interessada em estudar a língua em uma escola especializada, assim como pode ser pai de aluno, ou o próprio aluno. Ao verem fotografias, essas pessoas podem imaginar aquelas situações representadas como reais acontecimentos e vivências naquele espaço de aprender inglês e outros idiomas, ainda que sejam não reais daquele contexto específico. Isso porque as imagens podem ter sido originalmente buscadas em bancos de imagens na Internet, o que não consistiu em investigação para este trabalho, pois não é o foco. Independente de como tenham sido conseguidas, o que importa a esta pesquisa é o uso feito das imagens nos sites das escolas.

Nestas fotografias, os participantes humanos representados são, em sua maioria, do sexo feminino: mulheres adultas em 14 imagens e meninas em 8 imagens, totalizando 22 fotografias. Os participantes masculinos aparecem em 20 fotografias (13 como adultos e 7 como crianças). Assim, percebe-se certo equilíbrio de representação dos agentes aprendizes em termos de gênero. Entretanto, em 34 fotografias esses aprendizes são brancos, e negros aparecem em apenas 08 fotografias. Isso mostra que o ensino de inglês em escolas de línguas ainda é previsto como algo disponível e frequentado, predominantemente, por pessoas de cor branca e com aparência de serem pessoas com boa situação financeira e social (bem vestidos, arrumados, felizes, centrados no ato de aprender). Isso parece construir uma ideia de espaço em que não necessariamente haveria diversidade social ou étnico-racial. Se as imagens escolhidas para veiculação nos sites institucionais procuram revelar e divulgar o que acontece na escola particular especializada em idiomas, prevê-se que aprender língua estrangeira, especificamente, inglês, é algo conferido a uma parcela da população, preferencialmente jovem e adulta, não a uma diversidade de aprendizes.

Quanto às ações mais comuns desempenhadas pelos participantes humanos, observou-se o seguinte: 
Tabela 1: Ações mais comuns em narrativas visuais do aprender inglês em fotografias.

\begin{tabular}{|l|l|l|l|l|l|l|l|}
\hline Ações & Olhar & Sorrir & Escrever & Reagir & Ler & Ouvir & Conversar \\
\hline $\begin{array}{l}\text { Quantidade de } \\
\text { fotografias }\end{array}$ & 16 & 15 & 10 & 6 & 4 & 4 & 3 \\
\hline
\end{tabular}

Fonte: Dados de pesquisa, elaborado pelo autor.

Processos de ação relacionados ao "pensar e comunicar" (olhar, ler, escrever, ouvir, conversar) aparecem no corpus com certa frequência, e em todas essas ocorrências não há uso de balões. O estudar e o aprender são ações cognitivas, e estão relacionadas a outras ações como ler, escrever, olhar, ouvir, as quais envolvem os sentidos - visão, audição - e a fala ou a escrita. A maior ocorrência do processo de olhar está relacionada com outras ações como escrever (e olha-se para o que se escreve), ler, prestar atenção ao que é explicado (ouve-se e olha-se para quem explica e o que é explicado). São processos transacionais em sua maioria, em que se vê na imagem a meta das ações.

O processo de sorrir remete à alegria, satisfação, que pode ser uma ação e ao mesmo tempo uma reação a outra pessoa ou outro evento. A frequência alta desse processo no corpus analisado remete ao caráter publicitário do site institucional, o qual procura dar a entender que estudar línguas naquele estabelecimento é algo prazeroso, descontraído, traz felicidade e satisfação pessoal, implica bom relacionamento entre as pessoas envolvidas: alunos, colegas e professores.

De modo geral, as ações e reações representadas nas narrativas visuais em fotografias nos sites pesquisados, enfocando o aprender, são classificadas da seguinte maneira, como exposto na tabela 2.

Tabela 2: Processos de ação e reação em imagens relacionadas ao aprender inglês

\begin{tabular}{|l|l|l|l|l|l|l|}
\hline Processos & $\begin{array}{l}\text { Ação } \\
\text { transacional }\end{array}$ & $\begin{array}{l}\text { Ação não } \\
\text { transacional }\end{array}$ & $\begin{array}{l}\text { Ação } \\
\text { bidirecional }\end{array}$ & $\begin{array}{l}\text { Reação } \\
\text { transacional }\end{array}$ & $\begin{array}{l}\text { Reação não } \\
\text { transacional }\end{array}$ & $\begin{array}{l}\text { Reação } \\
\text { bidirecional }\end{array}$ \\
\hline Quantidade & 28 & 02 & 03 & 07 & 03 & 03 \\
\hline
\end{tabular}

Fonte: Dados de pesquisa, elaborado pelo autor.

As ações transacionais têm como meta, em sua maioria, a língua sendo estudada, ou o conhecimento. Em outras palavras, as ações são direcionadas ao que se estuda: língua, textos, regras, léxico. Em muitas imagens, podem ser vistos estudantes com olhares e braços direcionados a objetos como livros, computadores, cadernos (estão escrevendo, lendo, e demonstra-se que estão pensando - uma ação mental não representada por balões), e nesses objetos, deduz-se, encontra-se o que se está aprendendo - a língua. Essas ações estão inteiramente relacionadas ao estudar, ao aprender. Há imagens em que a figura do professor aparece, direcionando o olhar dos aprendizes, mostrando coisas ou fazendo junto com eles. Em alguns casos a meta são os dispositivos móveis, o que, junto com a aparição do computador, mostra que aprender idiomas é estar conectado, usando tecnologia, da mesma maneira que usar a tecnologia atual implica saber línguas. 
Isso leva a interpretação a dois pontos. Primeiro, que estudar inglês ou outras línguas naquelas escolas é fazer uso de tecnologias, acrescentando algo diferente às aulas convencionais. Segundo, o mundo contemporâneo, todo conectado, exige que se saiba a língua para que se possa agir nesse mundo.

Já os processos não transacionais remetem a ações cujas metas não contemplamos. Seria o caso, por exemplo, do aluno que age levantando a mão para falar, possivelmente com olhar direcionado ao professor, o qual não é mostrado, tampouco coisas sobre a aula (ver Figura 6 adiante).

Com relação aos instrumentos e ao cenário que mais aparecem nas imagens narrativas, tem-se que a sala de aula ainda é o lugar mais retratado em que acontece a aprendizagem (16 ocorrências). Nesse ambiente, estudantes aparecem, ora estudando, ora prestando atenção em alguma coisa representada ou não na imagem. Outros cenários que aparecem com menos frequência são: sala de estudo (04 ocorrências), laboratório de línguas (3 ocorrências), escritório (02 ocorrências), e ambiente aberto (02 ocorrências). Em 16 imagens o cenário não aparece claramente (é desfocado), ou não aparece. Já com relação aos instrumentos portados pelos participantes, o livro e o lápis são os mais comuns (lápis em 09 imagens, livro em 07 imagens). Tem-se ainda a utilização de outros instrumentos, como o computador (em 05 imagens) e o tablet (em 05 imagens), seguidos de caneta, fone de ouvido, celular, globo terrestre.

As imagens a seguir são exemplos do que foi exposto até então.

Figura 3: Escola 1 imagem 1

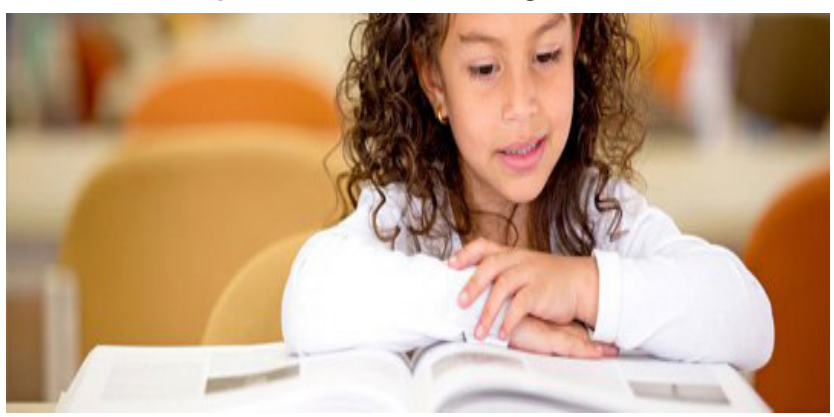

Fonte: Dados da pesquisa.

Figura 5: Escola 4 imagem 9

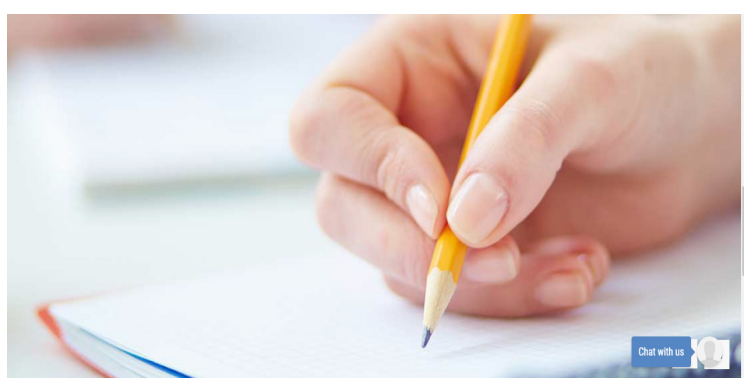

Fonte: Dados da pesquisa.
Figura 4: Escola 1 imagem 10

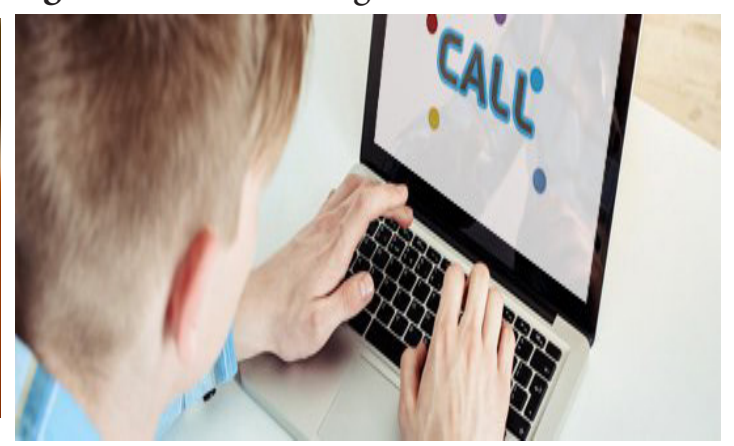

Figura 6: Escola 3 imagem 1

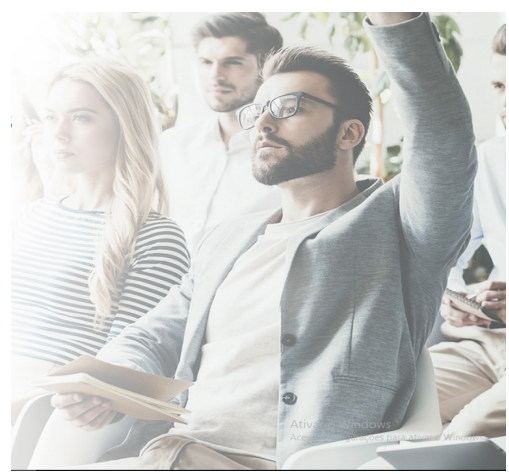


A imagem 1 da escola 1 (Figura 3) aparece em diversas seções do site, em que informações bem diferentes são veiculadas pelo texto verbal: "Cursos de inglês - Baby class - Material didático desenvolvido para criança / Cursos de inglês - Kids' Cour$s e$ - professores treinados". Percebe-se que a imagem da criança, neste caso, retrata uma menina lendo algo no livro em espaço pouco mostrado (desfocado), portanto, é uma ação (ler) denotando o estudar, ação transacional, pois poderíamos traçar um vetor partindo dos olhos da menina direcionados ao livro que lê. A imagem procura mostrar que sua ação leva à aprendizagem de maneira tranquila, considerando o semblante da menina, a qual demonstra certa felicidade ao executar a tarefa.

$\mathrm{Na}$ imagem 10 da escola 1 (Figura 4) aparece um adolescente de costas para o observador, numa situação de estudo usando o computador para acessar algo (mas só aparece a sigla CALL). Essa imagem mostra processo de ação transacional, pois a ação do adolescente é direcionada ao computador, o que se pode comprovar se traçarmos vetores partindo de seu corpo, os quais serão direcionados à tela do computador. A imagem aparece repetidamente quando se acessa várias seções do site: "Cursos de inglês - Teen course -Quando você vê, já está aprendendo com o CALL./ Cursos de inglês - Adult course -Quando você vê, já está aprendendo com o CALL./ Cursos de inglês - Business English -Quando você vê, já está aprendendo com o CALL”. Nestas seções, procura-se relacionar o aprender língua com o uso da tecnologia digital para diferentes alunos (adolescentes, adultos ou executivos), sempre com a mesma imagem.

Na imagem 9 da escola 4 (Figura 5), tem-se a fotografia da mão de uma mulher escrevendo com lápis numa folha. Não se pode ver o que está sendo escrito mas isso denota que a pessoa está estudando. Percebe-se o escrever, uma ação transacional, pois o braço e a mão estão direcionados ao que se escreve no papel. Poderia não ser uma imagem que represente aprender língua especificamente, como muitas das imagens coletadas (por exemplo, Figuras 3 e 6 aqui apresentadas), mas ao aparecer em um site de escola particular especializada em idiomas, e na seção "Nossos cursos - Preparatórios", a imagem exerce o papel de representar o aprender inglês, como todas as demais do corpus. Isso pode indicar que o ato de aprender idioma, por mais especificidade que tenha, e que faça com que existam escolas especializadas, não é representado como uma tarefa diferente do aprender outros conteúdos.

A Figura 6 - imagem 1 da escola 3 - é veiculada na seção "Para adultos". Retrata um grupo de alunos prestando atenção à aula com olhos direcionados a algo fora da imagem. Um aluno em posição de destaque (primeiro plano) levanta a mão como que querendo perguntar algo; na outra mão segura um livro ou algo para anotar - ações não transacionais, direcionadas para algo não mostrado. Outro, atrás, não destacado, anota algo - uma ação transacional. O cenário, pouco mostrado, é uma sala de aula, pois é possível deduzir que a ação é direcionada a um professor, pelo que se conhece da ação de assistir aula, em termos mais tradicionais: alunos sentados têm dúvidas e se comportam daquela forma para saná-las com o docente. Livros, lápis e caneta são os instrumentos mais comuns nessas situações - instrumentos tradicionais usados nas escolas em geral. 
Percebe-se, na análise até o momento, que o aprender línguas estrangeiras é representado, pelas escolas especializadas no ensino de idiomas, como algo que remete a prazer, seriedade, utilização de recursos diversos, conexão com rede de Internet, protagonismo do aluno, organização, situações e ambientes ideais com poucos alunos. Estes alunos pouco interagem entre si (por exemplo, Figuras 6 e 7), e embora estejam juntos, nem sempre estão interagindo, refletindo que o aprender seja uma ação individual. É a ideia de protagonismo do aluno, o que também pode ser relacionado com a pouca aparição nas imagens da figura do professor, o que ocorre apenas em 09 das 41 fotografias (como na Figura 7).

Figura 7: Escola 1 imagem 16

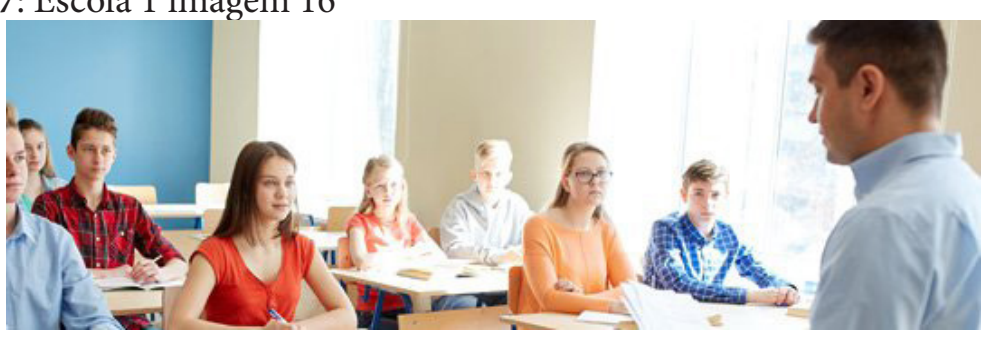

Fonte: Dados da pesquisa.

Em termos interpessoais, observa-se, no corpus, que as fotografias, em sua maioria, apresentam situações de oferta, isto é, o que se mostra é para ser contemplado pelo observador, não o convida a interagir com os participantes representados (exemplo, Figuras 3 a 7 nesta seção). Ao mesmo tempo, a maioria das fotografias trazem os participantes representados em tomada média (Figuras 1, 6 e 7, por exemplo) ou curta (por exemplo, as Figuras 3, 4, e 5), implicando certa identificação do observador com as pessoas e as situações mostradas. Se o observador é, ou pode ser, aluno daquele estabelecimento, espera-se que ele vivencie situações como aquelas e se veja como aquelas pessoas, aprendendo línguas em ambientes agradáveis, com recursos pedagógicos disponíveis (lápis, caneta, papel, livros, computadores, fones de ouvido, dispositivos móveis como smartphone e tablet).

Quanto aos aspectos composicionais das imagens fotográficas, percebe-se uma ênfase no processo de aprender em si por meio da centralização, na imagem, do sujeito aprendiz ou da ação que leva ao aprendizado, ao mesmo tempo em que esses elementos são colocados em primeiro plano (um recurso de saliência) em oposição a um cenário às vezes desfocado. A Figura 3, por exemplo, mostra a centralização da menina e da ação de ler, e o cenário em que essa ação acontece está desfocado em segundo plano, assim como na Figura 6, em que está ao centro e em primeiro plano um aprendiz sério, adulto, que age direcionado provavelmente ao professor (este, fora da imagem) querendo questionar, enquanto na mesma imagem os colegas são colocados em posição periférica e em segundo plano. Esses colegas fazem parte da situação mas pouco demonstram, naquele momento fotografado, ações que remetem ao aprender de maneira agentiva. Nas 
Figuras 4 e 5, por exemplo, tem-se a centralização do instrumento utilizado pelo aprendiz para promover a aprendizagem do idioma: o computador e o ato de escrever com lápis e papel.

A Figura 7 é um dos poucos exemplos em todo o corpus em que não há uso do recurso de centralização, mas de polarização horizontal, em que a imagem dos alunos ocupa mais de dois terços da fotografia em posição de informação dada, conhecida pelos observadores, enquanto o professor é posto em situação de informação nova, e que não interage com o observador da imagem, de costas para ele, embora em primeiro plano. O foco da imagem é nos aprendizes, retratados de maneira mais clara, mais objetiva, de frente para o observador, que estão em aula numa situação tranquila, sala organizada em fileiras (sala de aula convencional já conhecida), todos bem aparentados, jovens bem comportados, bem vestidos e de cor branca denotando um espaço homogêneo e idealizado de aprendizagem da língua estudada, o qual traria satisfação.

Duas imagens do corpus são infográficos, como já mencionado: a imagem 11 da escola 1 e a imagem 2 da escola 3. Apenas a segunda delas é reproduzida aqui por questões éticas, visto que a primeira imagem mencionada traz em si logomarca da escola de maneira que não é possível reproduzir sem tal marca. Entretanto, esta imagem é descrita a seguir.

A imagem 11 da escola 1 é um infográfico que mostra grupamentos de níveis representados por círculos (com nome da escola) em tons de azul, variando de mais claro ao mais escuro à medida que o nível avança. Cada nível de proficiência e fluência é posto abaixo numa sequência explicada que segue a ordem: Essential Fluency, Intermediate Fluency, Advanced Fluency e Master Fluency. Linhas indicam o movimento de ação de mudança de nível ou grupamento de níveis. O elemento verbal descreve cada grupamento e, na descrição anterior, lê-se: "A cada nível você evolui um pouco e sobe mais um degrau para alcançar seus sonhos e objetivos". Mas a direção das setas tendo em vista o grupamento de nível subsequente é para baixo, como se fosse do essencial (básico) ao que se pode alcançar (o domínio master). Parece ser um processo de conversão (embora não seja ciclo), como o próximo infográfico descrito, em que se percebe que as ações tomadas em determinado nível, junto com o que acontece nos outros, convergem para um objetivo a ser alcançado, que é o domínio de fluência master.

O segundo infográfico, reproduzido na Figura 8, é a imagem 2 da escola 3. Várias ações estão escritas em círculos que são ligados uns aos outros por meio de setas com direcionamento como se uma ação levasse a outra. O esquema em forma de quadrado é externo a outro circular denominado ciclo de aprendizagem (ao centro), em que ações também convergem e se encontram num círculo. As ações escritas executadas por professores ou avaliadores são: orientação, análise de nível, aconselhamento, instrução, confirmação, apoio, revisão, certificação. Depreende-se que a aprendizagem é decorrente das ações de agentes como professor ou coordenador, os quais não são mencionados. Isso mostra que o foco é em como a aprendizagem acontece ou deve acontecer, como algo determinado a qualquer aluno, desde que ele se insira no esquema independente de outros fatores. 
Figura 8: Escola 3 imagem 2

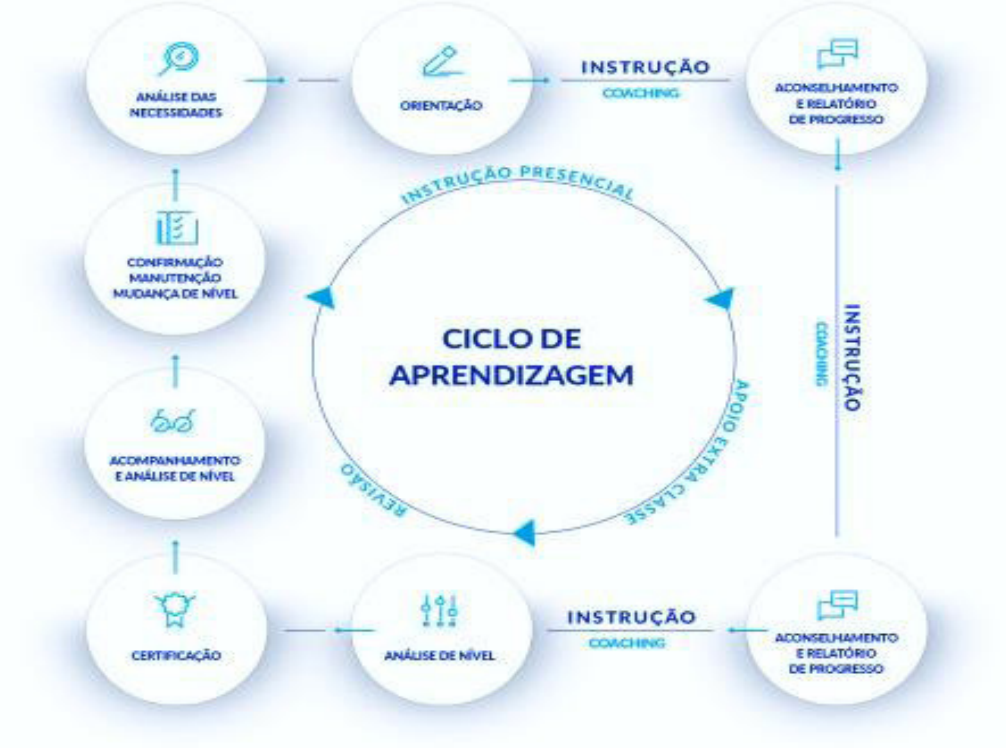

Fonte: Dados da pesquisa.

No infográfico da Figura 8, há uso das formas geométricas círculo e quadrado, os quais em nossa cultura ocidental remetem, respectivamente, a infinitude e continuidade, retidão, honestidade e determinação (DONDIS, 2006). Assim, o esquema mais externo, em quadrado, é determinado a acontecer e ser sempre daquela maneira, julgado ser correto, organizado e que acontece a partir de ações contínuas representadas em círculos (análise de situação, orientação e aconselhamento, instrução, avaliação, aprovação), que vão remeter uma a uma à formação do esquema quadrangular levando à instrução. Ao centro, a palavra "ciclo de aprendizagem" é salientada em caixa alta, rodeada por setas que formam um círculo, denotando que a aprendizagem acontece mediante as ações contínuas e integradas de instrução, apoio e revisão. Trata-se de uma situação ideal e determinada de aprendizagem, certa e contínua, que dá credibilidade às informações sobre o curso promovido e vendido pela escola especializada. Tal maneira de expor a aprendizagem está em consonância com as imagens fotográficas do restante do corpus, que, como dito, remetem a uma aprendizagem certa, determinada, ideal, em condições perfeitas de homogeneidade, de conforto e prazer.

A análise empreendida apresenta uma análise do discurso sobre aprender línguas presente em imagens de sites de escolas de idiomas e evidencia as representações visuais desse processo. Com isso, subsidia as considerações apresentadas a seguir.

\section{Considerações Finais}

O objetivo desse artigo foi apresentar uma análise do discurso construído sobre aprender línguas estrangeiras por meio do uso de imagens em sites de escolas de idiomas. Como referencial teórico, adota-se a visão sociossemiótica da linguagem, em que se inclui a Gramática do Design Visual (KRESS e VAN LEEU- 
WEN, 2006). Considerou-se que este discurso veiculado por imagens evidencia representações sociais desse processo de aprender línguas, as quais são construídas e veiculadas pelas escolas especializadas em idiomas para a comunidade em geral. A análise do corpus levou em conta 43 imagens de representação narrativa veiculadas em sites de quatro escolas com unidades em muitas localidades no país. Acredita-se que o referencial teórico e o corpus permitiram o cumprimento do objetivo proposto pelo que se expôs no item sobre análise dos dados.

A análise evidencia que as narrativas visuais utilizadas nos sites em diversas e diferentes seções (muitas vezes usadas repetidamente) ajudam a construir o discurso das instituições com participantes ficcionais, e revelam um ideal de aprendizagem de idiomas. Esse ideal inclui aprender de maneira assertiva, determinada, com prazer, seriedade. Os alunos estão concentrados e comportados, protagonizando ações que levam à aprendizagem. São retratados como agentes de ações de recepção da língua com mais frequência do que de produção oral e escrita, ações relacionadas à percepção e à cognição: olhar, ouvir, ler, estudar, prestar atenção, demonstrar vontade de questionar. A aprendizagem parece acontecer com a utilização de recursos diversos que estimulam e representam esse aprender (livros, cadernos, fones de ouvido, computadores, dispositivos digitais móveis). Há organização, situações de homogeneidade e ambientes confortáveis, limpos, bonitos, organizados, descontraídos, com poucos alunos, semelhante aos outros lugares retratados em que o aprendiz esteja, isto é, em casa, no trabalho, em ambientes de lazer. E estar em companhia de outros alunos no momento de aprendizagem não necessariamente implica interação, pois os alunos muitas vezes estão em sala de aula, executam a tarefa, mas não necessariamente interagem. A situação de sala de aula retratada no corpus aproxima-se da descrita e analisada por Pimenta (2001), em ambientes de ensino regular, isto é a sala de aula organizada em fileiras e com alunos sentados todos na mesma direção como sinal de mais obediência, mais respeito, mais docilidade, mais controle, o que, acredita-se, geraria mais concentração e consequentemente aprendizagem.

Além dos aspectos ideacionais, as representações são construídas também por aspectos composicionais que mostram a centralização do ato de aprender nas imagens, e reforçam o caráter agentivo do aprendiz em alguns momentos, ou a passividade em ambientes tranquilos e organizados. Em termos interpessoais, espera-se que o observador (leitor ou visitante do site institucional) contemple essas ações e situações e se identifique de certa maneira com um aprender comedido, descontraído, mas ao mesmo tempo satisfatório e possível. Parece haver uma esperança, por parte das instituições veiculadoras desse discurso, de que o observador ou visitante dos sites institucionais, ao se identificar com tais situações, sendo ou vindo a ser aluno daquela escola, contemple as situações ideais e também se identifique com os aprendizes ali representados.

Esse é um discurso institucional e também publicitário dessas escolas, que por meio das imagens enfatiza a situação prazerosa de aprender mais que o método em si, ou a figura do professor competente. Com isso, os dados se diferenciam parcialmente dos apresentados por Coracini (2003) quando esta 
pesquisadora analisou peças publicitárias impressas de escolas semelhantes às desta pesquisa, não enfatizando o uso de imagens. Essa autora mostra em seu trabalho como a língua torna-se, no discurso publicitário das escolas, objeto de consumo que satisfaz o "aluno-cliente" enfatizando, dentre outras coisas, preços acessíveis e tradição (tempo de atuação da instituição). As imagens que fazem parte da presente pesquisa mostram a ênfase em outro elemento: o prazer de aprender. Entretanto, alguns dados apresentados por Coracini (2003) se assemelham aos dados desta pesquisa em tela, como por exemplo a idealização do lugar para aprender idioma com ajuda de recursos tecnológicos digitais, professores amigáveis e empenhados.

$\mathrm{Na}$ pesquisa aqui relatada há uma representação idealizada da aprendizagem de línguas estrangeiras, pois sabe-se que nem sempre se tem, nessas escolas, crianças, adolescentes e jovens que ali frequentam com objetivos definidos, mas sim por imposição social da família, portanto, nem sempre sorridentes, comportados, confiantes e motivados. Também, sabe-se que nem sempre há, em períodos curtos de aula, uso de dispositivos móveis ou computadores, tampouco os aprendizes estão sempre satisfeitos com as aulas ou sempre dispostos, com tempo para estudos, como os dados dessa pesquisa deixam a entender. Embora os recursos tecnológicos sejam uma realidade nesses contextos mais que nas escolas de ensino regular, o que se mostra é o uso desses atrelados ao saber o idioma, mais que como recurso para aprender. Estar conectado pressupõe saber a língua, mas não se enfatiza que estando conectado se está aprendendo. Enfatizam-se a contemporaneidade, marcada pela tecnologia digital; e o processo de aprender idealizado, às vezes ainda um aprender tradicional (salas dispostas em fileiras, ações controladas que levam os alunos ao sucesso). Ao contrário dos dados de Coracini (2003), não se enfatiza, nas imagens, a tradição das escolas atuando no ramo há décadas como garantidor de sucesso. Ao mesmo tempo, embora seja um discurso propagandístico e institucional, as imagens remetem ao fato de que a aprendizagem é possível, mas é para poucos alunos, pois as turmas retratadas não são numerosas e há pouca diversidade étnico-racial e social.

A análise apresentada neste artigo ajuda a mostrar que o discurso institucional das escolas particulares especializadas em ensino de idiomas reforça a ideia comumente veiculada na sociedade de que elas propiciam o ambiente ideal para aprender outra língua em detrimento do ensino de línguas na escola regular pública ou privada. Nesta, não há, muitas vezes, as condições ideais e idealizadas mostradas nas imagens para que o aprender aconteça de maneira agradável, determinante, edificante e bem-sucedida. Ao contrário, as salas têm muitos alunos, nem sempre são bonitas, iluminadas, arejadas e aconchegantes, nem sempre a alegria é estampada nos rostos dos alunos ou de professores, também não há, frequentemente, os recursos e instrumentos mostrados: livros, computadores, dispositivos digitais móveis. Trata-se de uma visão de que a aprendizagem de idiomas com qualidade e sucesso é ainda direcionada a uma parte da população, a pessoas que se identificam com os alunos ali retratados, e que podem pagar 
para que esse aprender aconteça.

Considerando que "as imagens formulam mundos, estimulam práticas culturais", e que na contemporaneidade elas "produzem nossas relações, concepções e conhecimentos no e sobre o mundo" (CUNHA 2015, p 70-71), o que dialoga com a noção de representações e a teoria de linguagem adotadas neste trabalho, percebe-se, pelo exposto neste artigo, como as imagens veiculadas pelas escolas de idiomas produzem representações do ato de aprender, estimulando e reforçando a concepção e a prática elitistas e idealizadas de que o sucesso desse aprender só é possível ali, na escola especializada, e não na escola regular.

\section{Referências}

ALMEIDA FILHO, J. C. P. Linguística Aplicada, Ensino de Línguas e Comunicação. 4 ed. Campinas: Pontes Editores, Arte Língua, 2011.

BARCELOS, A. M. Narrativas, crenças e experiências de aprender inglês. Linguagem \& Ensino, v. 9, n. 2, jul./dez. 2006, p. 145-175.

CORACINI, M. J. F. O discurso publicitário sobre escolas de línguas e a constituição da identidade. Letras \& Letras, Uberlândia, 19 (1) jan./jun. 2003, p. 53-74.

COSTA, S. R. Dicionário de gêneros textuais. Belo Horizonte: Autêntica, 2008.

CUNHA, S. V. R. Qual o lugar dos materiais visuais na pesquisa em educação? Educação em Revista. Belo Horizonte: vol. 31, n. 1, janeiro - março/2015, p.98120.

DONDIS, D. A Sintaxe da Linguagem Visual. São Paulo: Martins Fonte, 2006.

DUTRA, Deise Prina. Formação de professores: colaboração sem fronteiras. In. FERREIRA, Maria Cristina F. Dalacorte; REICHMANN, Carla Lynn; ROMERO, Tania Regina de Souza (org.) Construções Identitárias de Professores de Línguas. Campinas: Pontes Editores, 2016, pp. 87-102.

GASKELL, G. Entrevistas individuais e grupais. In.: BAUER, M.W. \& GASKELL, G. (org.) Pesquisa Qualitativa com Texto, Imagem e Som - um manual prático. 7 ed. Petrópolis: Vozes, 2008, p. 64-89

HALLIDAY, M. A. K. An Introduction to Functional Grammar. 2 ed. London: Arnold, 1994.

HALLIDAY, M. A. K; MATHIESSEN, C. An Introduction to Functional Grammar. 3 ed. London: Hodder Education, 2004.

HEMAIS, B. Genres in English Language Course Books: Teaching Words and Images. In.: GONÇALVES, G. R.; ALMEIDA, S. G.; PAIVA, V. L. M. O; JÚNIOR, A. S. R. New Challenges in Language and Literature. Belo Horizonte: Faculdade de Letras da UFMG, 2009, pp. 67-80.

JODELET, D. Répresentation sociale: phénomènes, concept et théorie. In.: MOSCOVICI, S. (ed.) Psychologie Sociale. 5 ed. Paris: PUF Fondamental, Presses Universitaires de France, 1995, p. 357-378.

JOLY, M. Introdução à Análise de Imagem. Lisboa, Ed. 70, 2007.

KAWAKAMI, T. T.; VEIGA, A. I. M. A popularização da fotografia e seus efeitos: Um estudo sobre o a disseminação da fotografia na sociedade contemporânea e suas consequências para os fotógrafos e suas produções. Projética - Revista Científica de Design: Londrina, v. 3, n. 1 l, julho 2012, p. 168-182.

KRESS, G.; VAN LEEUWEN, T. Multimodal Discourse. Continuun Books, 2001. 
KRESS, G.; VAN LEEUWEN, T. Reading Images - the grammar of visual design. 2 ed. London, New York: Routledge, 2006.

KRESS, G. Multimodality: a social semiotic approach to contemporary communication. New York, London: Routledge, 2010,

MOITA LOPES, L. P. (org.). Por uma Linguística Aplicada Indisciplinar. São Paulo: Parábola Editorial, 2006.

MOSCOVICI, S. Representações Sociais: Investigações em Representações Sociais. 4 ed. Petrópolis: Vozes, 2003.

NATIVIDADE, C.; PIMENTA, S. A Semiótica Social e a Multimodalidade. In.: PIMENTA, S; LIMA, C. H. P; AZEVEDO, A. M. T. Incursões Semióticas: teoria e prática de Gramática Sistêmico-Funcional, Multimodalidade, Semiótica Social e Análise Crítica do Discurso. Rio de Janeiro: Livre Expressão Editora, 2009.

OLIVEIRA, P. R. O Processo de escolha do livro didático de História numa perspectiva discursiva. Dissertação de Mestrado. Programa de Pós-Graduação em Estudos de Linguagens - Centro Federal de Educação Tecnológica de Minas Gerais, 2015.

PIMENTA, S. A Semiótica Social e a Semiótica do Discurso de Kress. In.: MAGALHÂES, C. Reflexões sobre a Análise Crítica do Discurso. Belo Horizonte: FALE / POSLIN / UFMG, 2001, pp. 185-206.

PIMENTA, S.; LIMA, C. H. P; AZEVEDO, A. M. T. Incursões Semióticas: teoria e prática de Gramática Sistêmico-Funcional, Multimodalidade, Semiótica Social e Análise Crítica do Discurso. Rio de Janeiro: Livre Expressão Editora, 2009.

REPOLÊS, M. C. P. Coleções didáticas de Língua Inglesa/ PNLD: a apropriação do material didático por professores e alunos de escolas públicas mineiras. Tese de doutorado. Programa de Pós-Graduação em Estudos de Linguagens - Centro Federal de Educação Tecnológica de Minas Gerais, 2019.

RIOS, S. O.; COSTA, J. M. A.; MENDES, V. L. P. A fotografia como técnica e objeto de estudo na pesquisa qualitativa. Discursos fotográficos, Londrina, v.12, n.20, jan./ jul. 2016, p. 98-120.

SÁ, C. P. A Construção do Objeto de Pesquisa em Representações Sociais. Rio de Janeiro: EDUERJ, 1998.

SILVA, E. R.; ABUD, M. J. M.; CASTRO, S. T. R. (org.) Representações docentes e discentes em contextos educativos. Taubaté: Cabral Editora e Livraria Universitária, 2010.

SILVA, R. C. Representações do livro didático de inglês: análise dos discursos de produtores e usuários com base na linguística sistêmico-funcional. Tese de doutorado. Rio de Janeiro: PUC-Rio Departamento de Letras, 2012.

VAN LEEUWEN, T. Ten reasons why linguists should pay attention to visual communication. In.: LE VINE, P.; SCOLLON, R. Discourse and Technology: multimodal discourse analysis. Washington D.C., Georgetown University Press, 2004, pp. 7-19.

VAN LEEUWEN, T. Introducing Social Semiotics. London / New York: Routledge, 2005.

Recebido em: 30/06/2019

Aceito em: 02/12/2019 